${ }^{2}$ VA Puget Sound, Seattle, WA, USA.

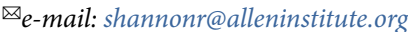

Published online: 24 March 2020

https://doi.org/10.1038/s41684-020-0509-1
References

1. Animal Welfare Act, $\$ 2132$ https://naldc.nal.usda.gov/ download/5969370/PDF

2. USDA APHIS. Regulated Businesses (Licensing and Registration) website. https://www.aphis.usda.gov/aphis/ourfocus/ animalwelfare/ct_awa_regulated_businesses
3. USDA APHIS. Licensing and Registration Under the Animal Welfare Act. Guidelines for Dealers, Exhibitors, Transporters, and Researchers. https://www.aphis.usda.gov/animal_welfare/ downloads/aw/awlicreg_gray-book.pdf

4. Brown, P. \& Gipson, C. Lab Anim NY 39, 68 (2010).

5. Animal Welfare Act Regulations, $\$ 2.31$ https://naldc.nal.usda.gov/ download/5969370/PDF

\title{
Who needs a license? Review of the facts needed
}

$\Lambda$ ccording to Animal Welfare Act (AWA) Sections 2131 and 2132(f)

9 CFR, Part 1 Subject: Licensing Sales of Dead Animals Policy \#201, the definition of a 'dealer' is "any person who... buys or sells ... any dog or other animal whether alive or dead for research, teaching, exhibition, or use as a pet."

Licenses are not required for any person who acquires a dead animal (other than a dog or cat) and then sells it, or any person who acquires a dead dog or cat (or parts) from a USDA licensed dealer or municipal, county, or state pound/shelter and then sells it. Licenses are required for any person who acquires a dead dog or cat (or parts) from private, unlicensed sources, to sell for covered purposes or for any person who acquires any live covered animal and subsequently euthanizes that animal to sell for a covered purpose. This last example is what the 'not for profit' animal shelter is doing. Therefore, they need a license from the USDA.

According to AWA ( $\$ 2133 ; \$ 2136)$ and the AWAR (\$1.1, Dealer; $\$ 2.1$, a,3, 5i-viii), "If a private shelter provides animals to a research facility, it must be licensed with APHIS/AC as a dealer and must comply with all AWA regulations governing dealers, which do not include a requirement for an IACUC."2 This statement appears to indicate that the private shelter specified as 'not for profit' would be classified as a dealer, therefore needing a license.

APHIS/AC Policy 20 requires the licensing of distributors of dead animals or parts only if the dealers or persons are engaged in commerce and seemingly would exclude pounds as a regulated source, providing that no money changed hands. While it is safe to conclude that the IACUC would not be required to approve the acquisition of cadaver animals donated from a pound, the involvement of a financial transaction may have different implications. IACUCs may want to carefully review and consider situations of cadaver donation from pounds given the animal welfare, public relations, and other implications related to the care, handling, and humane euthanasia practices at the source.

The IACUC does in fact have the authority to withhold purchasing of hearts from an unauthorized dealer, which, in this instance, the animal shelter has become. Martinelli can purchase hearts from any 'dealer' that has a license and continue his study until the animal shelter can complete the paperwork and receive their license. According to Reference, "The role and authority of the IACUC in the care, use, and oversight of research animals cannot be overstated and it is this somewhat unique premise that is at the core of animal use oversight in the US." Additionally, the authors state that "the IACUC must also review and approve all proposed activities involving the care and use of animals in research, testing, or teaching procedures and all subsequent significant changes of ongoing activities."
Regarding the issue of whether the veterinary school requires a dealer's license, I went on the USDA website to review the 582 page report of Active Licensees and Registrants. Every single United States Veterinary School has an animal resources division that requires a license. I see no reason to make this specific department at Great Eastern University get a license. They could use the license that Animal Care already has, plus, they are getting signed consent forms from the owners of these dogs that are being euthanized at the Veterinary School. As stated in the scenario, "most IACUC members who argued that the veterinary hospital was part of the university, and an internal transfer of funds from Martinelli to the hospital was not the same as a payment to a dealer." This is exactly how I view this situation.

Mary Ellen Goldberg

Independent Contractor, Boytnon Beach, FL, USA.

e-mail:mewhitester@gmail.com

Published online: 24 March 2020

https://doi.org/10.1038/s41684-020-0508-2

References

1. United States Department of Agriculture. Animal Care Policy Manual, p 42. https://www.umass.edu/research/sites/default/files/ usda_animal_care_policy_manual.pdf

2. Silverman J, Suckow MA, Murthy S. The IACUC Handbook 3rd Edition, pp 18-19. (CRC Press, Boca Raton FL, 2014).

3. Bradfield JF, Bennett BT, Gillett CS. Chapter 2 Oversight of Research Animal Welfare in the United States, Laboratory Animals Regulations and Recommendations for the Care and Use of Animals in Research, 2nd Edition, Ed. Javier Guillén, pp 17-18 (Academic Press/Elsevier, London, UK, 2018). 